\title{
A Spatial Configuration Effect on the Probability of Detection
}

\author{
Robert A. Frosch ${ }^{1}$, Fellow, IEEE
}

Abstract - This paper discusses a simple problem in detection theory using a model with a simple discretized space. This allows the probability problem to be analyzed algebraically to demonstrate that separate targets, independent before entering the detection space, do not have probabilistically independent detection probability distributions. Several variants of the basic case are discussed.

Index Terms - Detection probability, probabilistic independence, configural theory

\section{INTRODUCTION}

The problem discussed in this paper was originally motivated by analysis of naval mine fields. Naval mines are devices that detect the passage of a ship, and then explode under it to destroy it. In a naval mine field, mines are distributed in a channel, or a spatial region through which the ships must pass. In this paper I consider only the detection part of the process, ignoring questions of possible means for the destruction of the detected targets.

As discussed in the last section of the paper, the effects here described apply to a variety of real oceanic detection problems, and the conclusions not only make a considerable difference in the values, nature and structure of detection probabilities, they open the way to new ways for the design of detection probability distributions in space.

In this paper, space has been simplified by discretization into boxes to simplify the analysis, and to make the effects and the reasoning leading to the effects more transparent. Because of the discretization, the analysis requires only simple combinatorics and algebra for its solution. The result, however, is general, and is important in two senses:

1. Analysis of the probability of detection of a sequence of targets by a detector generally assumes that detections of separate targets arriving independently may be treated as probabilistically independent. Analysis of this simple case shows that this assumption is likely to be incorrect, and can lead to gross errors in detection

\footnotetext{
${ }^{1}$ Manuscript received: ; Revised: ; accepted First published:

Robert A. Frosch is with the Woods Hole Oceanographic Institution, Woods Hole, MA, and the Harvard Kennedy School, Cambridge, MA

Digital Object Identifier:
} 
probability distributions. The correct distribution of probability of detection can be very different from that derived in the independent case.

2. In designing detection systems the dependency effects may be used to design detection probability distributions that may be of advantage for the purposes of the system.

\section{THE GAME AND THE RULES}

Consider a row of 6 boxes numbered 1 through 6. (Figure 1) One of the 6 boxes is uniformly randomly selected, and a black ball (a detector) is placed in the box with the number selected. ( $B_{i}$ signifies a black ball in box $i$.) One of the four boxes 2,3 , 4 , or 5 is independently uniformly randomly selected, and a white ball (a target) is placed in the box with the number selected. ${ }^{2}$ ( $\mathrm{W}_{\mathrm{j}}$ signifies a white ball in box j.) Because the black ball can be placed into any one of 6 boxes, and the white ball can be independently placed into any one of 4 boxes, that process leads to some one of 24 distinct white-ball, black-ball configurations, each of which has probability $1 / 24$ of occurring.

If a white ball (target) is placed in the same box as the black ball, or in a box adjacent to the black ball (on either side), the white ball is detected. If the white ball is placed in any box not one of those three, the white ball is 'not detected'. In either case, the black ball remains in the same box in which it was originally randomly placed.

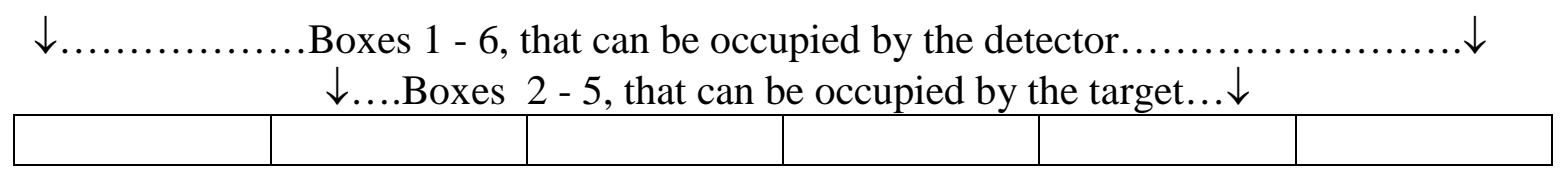

Figure 1: The Game setup.

\footnotetext{
${ }^{2}$ In the naval mine field case, the black ball $\mathrm{B}_{\mathrm{i}}$ represents an automatically replaced if exploded mine in the mine field, and a white ball $\mathrm{W}_{\mathrm{j}}$ represents a ship trying to transit the mine field. In an antiaircraft case, the black ball $\mathrm{B}_{\mathrm{i}}$ represents an immediately reloaded antiaircraft weapon system, and the white ball $\mathrm{A}_{\mathrm{j}}$ represents an aircraft trying to pass the antiaircraft weapon system.
} 
( $\mathrm{X}=$ detected, and $0 \mathrm{X}=$ not-detected $)$

\begin{tabular}{|l|l|l|l|l|l|l|}
\hline $\mathrm{W} \| \mathrm{B} \rightarrow$ & $\mathrm{B} 1$ & $\mathrm{~B} 2$ & $\mathrm{~B} 3$ & $\mathrm{~B} 4$ & $\mathrm{~B} 5$ & $\mathrm{~B} 6$ \\
\hline $\mathrm{W} 2$ & $\mathrm{X}$ & $\mathrm{X}$ & $\mathrm{X}$ & $0 \mathrm{X}$ & $0 \mathrm{X}$ & 0X \\
\hline W3 & $0 \mathrm{X}$ & $\mathrm{X}$ & $\mathrm{X}$ & $\mathrm{X}$ & $0 \mathrm{X}$ & 0X \\
\hline W4 & OX & 0X & $\mathrm{X}$ & $\mathrm{X}$ & $\mathrm{X}$ & 0X \\
\hline W5 & OX & 0X & 0X & $\mathrm{X}$ & $\mathrm{X}$ & $\mathrm{X}$ \\
\hline
\end{tabular}

Table 1: The Truth/Event Table of possibilities.

The "truth/event table" of possibilities is shown in Table 1. In this table a white ball placed in box W2 is detected only if the black ball is in B1, B2, or B3; etc. (X means 'detected', and OX means 'not detected'.) We also note that this table, set by the rules of the game and the disposition of the boxes, never changes, and is not contingent on events in the game.

\section{PROBABILITY NOTATION AND RULES}

In this work we need to consider probability rules and distributions. We use the probability notation and rules [1]:

$\operatorname{Pr}\{\mathrm{A}\}=$ Probability of $\mathrm{A}$

$\mathrm{AB}=\mathrm{A}$ and $\mathrm{B}$

$\operatorname{Pr}\{\mathrm{A}$ or $\mathrm{B}$ or both $\}=\operatorname{Pr}\{\mathrm{A}\}+\operatorname{Pr}\{\mathrm{B}\}-\operatorname{Pr}\{\mathrm{AB}\}$

If, and only if, $A$ and $B$ are independent: $\operatorname{Pr}\{A B\}=\operatorname{Pr}\{A\} \operatorname{Pr}\{B\}$.

If $A$ and $B$ are mutually exclusive, then $\operatorname{Pr}\{A B\}=0$, and

$\operatorname{Pr}\{\mathrm{A}$ or $\mathrm{B}\}=\operatorname{Pr}\{\mathrm{A}\}+\operatorname{Pr}\{\mathrm{B}\}$.

In all uses of the "or" rule in this paper, the variables concerned will be mutually exclusive. A target is either killed or not killed; it cannot be both. The black ball B can only be in one of positions $1,2, \ldots .6$, and a given white ball $\mathrm{W}$ can be only in one of the positions 2, 3, 4, 5 . All cases have been constructed so that the mean probability of detection (total detections divided by total possibilities) is $1 / 2$.

\section{THE FIRST TRIAL}

For the first trial, a number i from $1-6$ is uniformly randomly selected, and the detector (the black ball) is placed in the one of the 6 boxes Bi which has this number. A number $\mathrm{j}$ from 2 
to 5 is uniformly randomly and independently selected, and the target (the white ball) is placed in the one of the 4 boxes $\mathrm{Wj}$ which has this number. If the square in the truth/event table with coordinates $\mathrm{Bi}, \mathrm{Wj}$ has an $\mathrm{X}$ in it, white is detected; if it has an $\mathrm{OX}$ in it, white is not-detected. In either case, the black ball remains where it was originally placed.

$\begin{array}{lllllllll}1,2 \mathrm{X} & 2,2 & \mathrm{X} & 3,2 \mathrm{X} & 4,20 \mathrm{X} & 5,20 \mathrm{X} & 6,20 \mathrm{X} \\ 1,30 \mathrm{X} & 2,3 \mathrm{X} & 3,3 \mathrm{X} & 4,3 \mathrm{X} & 5,30 \mathrm{X} & 6,30 \mathrm{X} \\ 1,40 \mathrm{X} & 2,40 \mathrm{X} & 3,4 \mathrm{X} & 4,4 \mathrm{X} & 5,4 \mathrm{X} & 6,40 \mathrm{X} \\ 1,50 \mathrm{X} & 2,50 \mathrm{X} & 3,50 \mathrm{X} & 4,5 \mathrm{X} & 5,5 \mathrm{X} & 6,5 \mathrm{X}\end{array}$

Table 2: The "truth/event table’ for the first target encounter.

(The notation is that the first number is the location of the black ball, and the number after the comma is the location of the white ball.)

Table 2. shows the 'truth/event table' for the first target. Inspection of the truth/event table shows that, while the probability of the position of the black ball is independently uniformly distributed over the 6 positions, and the probability of the position of the white ball is independently uniformly distributed over the four positions allowed for it, the distribution of detections and non-detections of the white ball is not uniform over the six possible positions of the black ball. Given that the white ball was not detected:

the conditional probability of the black ball being in position 1 is 3/12 =1/4 the conditional probability of the black ball being in position 6 is 3/12 =1/4 the conditional probability of the black ball being in position 2 is $2 / 12=1 / 6$ the conditional probability of the black ball being in position 5 is $2 / 12=1 / 6$ the conditional probability of the black ball being in position 3 is $1 / 12=1 / 12$ the conditional probability of the black ball being in position 4 is $1 / 12=1 / 12$ The probability that the detector (black ball), which is in whatever box Bi was uniformly randomly selected for it, detects the target (white ball), given that the target is in whatever box $\mathrm{W}_{\mathrm{j}}$ was independently uniformly randomly selected for it, remains $1 / 2$. Regardless of which box the white ball target occupies, there are always three boxes (out of the six) in which the presence of a detector means that the white ball is detected. Since the probability of non-detection $=1$ minus the probability of detection, the probability of non-detection is also $1 / 2$. 


\section{THE SECOND TRIAL: THE CASE WITH AN ADDITIONAL TARGET}

At this point, if asked to consider what happens to another target ( $\mathrm{Y}$ ), and then asked for the joint detection probabilities for the fates of the two targets (X and $\mathrm{Y}$ ), most/all of us, and certainly anyone using standard Naval warfare analysis, or operations research practice, would say that the probabilities for target $Y$, who is going into the same situation, are the same as for target X. We would then say that the probability for the joint fates of the two targets would simply be the product of their individual fates. Thus the probability that both $\mathrm{X}$ and $\mathrm{Y}$ are detected is $1 / 4(\mathrm{P}\{\mathrm{XY}\}=1 / 4)$. The probability that neither is detected is $1 / 4(\mathrm{P}\{0 \mathrm{X} 0 \mathrm{Y}=1 / 4)$. The probability that $\mathrm{X}$ is detected, but not $\mathrm{Y}(\mathrm{P}\{\mathrm{X} 0 \mathrm{Y}\})$, or that $\mathrm{X}$ is not-detected $(\mathrm{P}\{0 \mathrm{XY}\})$, but $\mathrm{Y}$ is detected, each equal $1 / 4$, and thus the probability that one of $\mathrm{X}$ and $\mathrm{Y}$ is detected is $1 / 2$.

Let us now consider a second trial, in which the black ball (detector) remains where it was randomly placed in the first trial, and a new target (white ball) is uniformly randomly and independently placed in a box $\mathrm{j}$. The result may be obtained by examining the detection table for two trials jointly, using the original detection table to construct all the triples $\mathrm{Bi}, \mathrm{XjYk}$, and counting the various occurrences, where $\mathrm{X}$ is a detection in the first trial, $\mathrm{Y}$ a detection in the second trial, and $0 \mathrm{X}$ or $0 \mathrm{Y}$ means non-detection in the first or second trial respectively. The outcome table is shown as Table 3.

$\begin{array}{llllllllllllllllll}1,22 & \mathrm{X} & \mathrm{Y} & 2,22 & \mathrm{X} & \mathrm{Y} & 3,22 & \mathrm{X} & \mathrm{Y} & 4,22 & 0 \mathrm{X} & 0 \mathrm{Y} & 5,22 & 0 \mathrm{X} & 0 \mathrm{Y} & 6,22 & 0 \mathrm{X} & 0 \mathrm{Y} \\ 1,32 & 0 \mathrm{X} & \mathrm{Y} & 2,32 & \mathrm{X} & \mathrm{Y} & 3,32 & \mathrm{X} & \mathrm{Y} & 4,32 & \mathrm{X} & 0 \mathrm{Y} & 5,32 & 0 \mathrm{X} & 0 \mathrm{Y} & 6,32 & 0 \mathrm{X} & 0 \mathrm{Y} \\ 1,42 & 0 \mathrm{X} & \mathrm{Y} & 2,42 & 0 \mathrm{X} & \mathrm{Y} & 3,42 & \mathrm{X} & \mathrm{Y} & 4,42 & \mathrm{X} & 0 \mathrm{Y} & 5,42 & \mathrm{X} & 0 \mathrm{Y} & 6,42 & 0 \mathrm{X} & 0 \mathrm{Y} \\ 1,52 & 0 \mathrm{X} & \mathrm{Y} & 2,52 & 0 \mathrm{X} & \mathrm{Y} & 3,52 & 0 \mathrm{X} & \mathrm{Y} & 4,52 & \mathrm{X} & 0 \mathrm{Y} & 5,52 & \mathrm{X} & 0 \mathrm{Y} & 6,52 & \mathrm{X} & 0 \mathrm{Y} \\ 1,23 & \mathrm{X} & 0 \mathrm{Y} & 2,23 & \mathrm{X} & \mathrm{Y} & 3,23 & \mathrm{X} & \mathrm{Y} & 4,23 & 0 \mathrm{X} & \mathrm{Y} & 5,23 & 0 \mathrm{X} & 0 \mathrm{Y} & 6,23 & 0 \mathrm{X} & 0 \mathrm{Y} \\ 1,33 & 0 \mathrm{X} & 0 \mathrm{Y} & 2,33 & \mathrm{X} & \mathrm{Y} & 3,33 & \mathrm{X} & \mathrm{Y} & 4,33 & \mathrm{X} & \mathrm{Y} & 5,33 & 0 \mathrm{X} & 0 \mathrm{Y} & 6,33 & 0 \mathrm{X} & 0 \mathrm{Y} \\ 1,43 & 0 \mathrm{X} & 0 \mathrm{Y} & 2,43 & 0 \mathrm{X} & \mathrm{Y} & 3,43 & \mathrm{X} & \mathrm{Y} & 4,43 & \mathrm{X} & \mathrm{Y} & 5,43 & \mathrm{X} & 0 \mathrm{Y} & 6,43 & 0 \mathrm{X} & 0 \mathrm{Y} \\ 1,53 & 0 \mathrm{X} & 0 \mathrm{Y} & 2,53 & 0 \mathrm{X} & \mathrm{Y} & 3,53 & 0 \mathrm{X} & \mathrm{Y} & 4,53 & \mathrm{X} & \mathrm{Y} & 5,53 & \mathrm{X} & 0 \mathrm{Y} & 6,53 & \mathrm{X} & 0 \mathrm{Y} \\ 1,24 & \mathrm{X} & 0 \mathrm{Y} & 2,24 & \mathrm{X} & 0 \mathrm{Y} & 3,24 & \mathrm{X} & \mathrm{Y} & 4,24 & 0 \mathrm{X} & \mathrm{Y} & 5,24 & 0 \mathrm{X} & \mathrm{Y} & 6,24 & 0 \mathrm{X} & 0 \mathrm{Y} \\ 1,34 & 0 \mathrm{X} & 0 \mathrm{Y} & 2,34 & \mathrm{X} & 0 \mathrm{Y} & 3,34 & \mathrm{X} & \mathrm{Y} & 4,34 & \mathrm{X} & \mathrm{Y} & 5,34 & 0 \mathrm{X} & \mathrm{Y} & 6,34 & 0 \mathrm{X} & 0 \mathrm{Y} \\ 1,44 & 0 \mathrm{X} & 0 \mathrm{Y} & 2,44 & 0 \mathrm{X} & 0 \mathrm{Y} & 3,44 & \mathrm{X} & \mathrm{Y} & 4,44 & \mathrm{X} & \mathrm{Y} & 5,44 & \mathrm{X} & \mathrm{Y} & 6,44 & 0 \mathrm{X} & 0 \mathrm{Y} \\ 1,54 & 0 \mathrm{X} & 0 \mathrm{Y} & 2,54 & 0 \mathrm{X} & 0 \mathrm{Y} & 3,54 & 0 \mathrm{X} & \mathrm{Y} & 4,54 & \mathrm{X} & \mathrm{Y} & 5,54 & \mathrm{X} & \mathrm{Y} & 6,54 & \mathrm{X} & 0 \mathrm{Y} \\ 1,25 & \mathrm{X} & 0 \mathrm{Y} & 2,25 & \mathrm{X} & 0 \mathrm{Y} & 3,25 & \mathrm{X} & 0 \mathrm{Y} & 4,25 & 0 \mathrm{X} & \mathrm{Y} & 5,25 & 0 \mathrm{X} & \mathrm{Y} & 6,25 & 0 \mathrm{X} & \mathrm{Y} \\ 1,35 & 0 \mathrm{X} & 0 \mathrm{Y} & 2,35 & \mathrm{X} & 0 \mathrm{Y} & 3,35 & \mathrm{X} & 0 \mathrm{Y} & 4,35 & \mathrm{X} & \mathrm{Y} & 5,35 & 0 \mathrm{X} & \mathrm{Y} & 6,35 & 0 \mathrm{X} & \mathrm{Y} \\ 1,45 & 0 \mathrm{X} & 0 \mathrm{Y} & 2,45 & 0 X & 0 \mathrm{Y} & 3,45 & \mathrm{X} & 0 \mathrm{Y} & 4,45 & \mathrm{X} & \mathrm{Y} & 5,45 & \mathrm{X} & \mathrm{Y} & 6,45 & 0 \mathrm{X} & \mathrm{Y} \\ 1,55 & 0 \mathrm{X} & 0 \mathrm{Y} & 2,55 & 0 \mathrm{X} & 0 \mathrm{Y} & 3,55 & 0 \mathrm{X} & 0 \mathrm{Y} & 4,55 & \mathrm{X} & \mathrm{Y} & 5,55 & \mathrm{X} & \mathrm{Y} & 6,55 & \mathrm{X} & \mathrm{Y}\end{array}$

Table 3: The $6 \times 4 \times 4$ Outcome Table for Two Trials 
Counting occurrences in the columns, then the rows, and adding:

$\operatorname{Pr}\{0 X Y\}: \quad 3+4+3+3+4+3=20 / 96=5 / 24$

$\operatorname{Pr}\{\mathrm{X} 0 \mathrm{Y}\}: \quad 3+4+3+3+4+3=20 / 96=5 / 24$

$\operatorname{Pr}\{\mathrm{X} \mathrm{Y}\}: \quad 1+4+9+9+4+1=28 / 96=7 / 24$

$\operatorname{Pr}\{0 \mathrm{X} 0 \mathrm{Y}\}: 9+4+1+1+4+9=28 / 96=7 / 24$

The probability that the two targets suffer the same fate is greater than that they suffer different fates. Further:

$$
\operatorname{Pr}\{0 X\} \operatorname{Pr}\{Y\}=48 / 96 \times 48 / 96=1 / 2 \times 1 / 2=1 / 4=6 / 24 \text {, while } \operatorname{Pr}\{0 X Y\}=5 / 24,
$$

and therefore: $\operatorname{Pr}\{0 X Y\}$ is not $=\operatorname{Pr}\{0 X\} \operatorname{Pr}\{Y\}$ : (ie: $6 / 24$ is not $=5 / 24$ ).

Thus the occurrence of detection of the first white ball in the first trial, and detection of the second white ball in the second trial are, by the definition of independent, not independent, even when it may be said that "nothing happened" (ie: 0X) on the first trial.

However, this surprising result is not surprising. The position of the defender (black ball) was chosen by a uniformly random process, but the ball did land somewhere, and it stays where it landed. When the position of the black ball has been decided by the random process, the probability distribution of its (unknown) location is different from the uniform probability distribution of its (unknown) location before the random choice. The event $0 \mathrm{X}$ in the first trial being certain, tells us that, wherever the defender (black ball) is, it is more likely to be near B1 or B6 than near B3 or B4, and therefore the kill probability in the second trial is no longer uniformly random, but now depends upon where the uniformly randomly placed second white ball lands.

We may see this clearly by examining the probability of a position of the black ball conditional upon the fate of the white ball. By looking at the event/truth table we can see that, given that the white ball was not detected:

the conditional probability of the black ball being in position 1 is 3/12 =1/4 the conditional probability of the black ball being in position 6 is 3/12 =1/4 the conditional probability of the black ball being in position 2 is $2 / 12=1 / 6$ the conditional probability of the black ball being in position 5 is 2/12 =1/6 the conditional probability of the black ball being in position 3 is $1 / 12=1 / 12$ the conditional probability of the black ball being in position 4 is $1 / 12=1 / 12$ 
At this point, many readers may be reminded of the Monty Hall Problem, a famous case in which most people's probability intuitions are incorrect (even the probability intuitions of many eminent mathematicians trained in probability theory and statistics). [2]

\section{VI: THE GENERAL CASE FOR N TARGETS}

Having looked at the game results for 1 and 2 targets, let us now generalize to $\mathrm{N}$ targets. Consider $\mathrm{N}$ separate targets, of whom N-m are detected and $\mathrm{m}$ are not detected.

If $B$ is in 1 or 6 (which are mutually exclusive), there are $1^{(\mathrm{N}-\mathrm{m})}$ ways for $(\mathrm{N}-\mathrm{m})$ targets to be detected (by being in 2 if $\mathrm{B}$ is in 1 ; or 5 if $\mathrm{B}$ is in 6 ), and $3^{\mathrm{m}}$ ways for $\mathrm{m}$ targets to not be detected (by being in 3,4 , or 5 if $B$ is in 1 ; or 2,3 , or 4 if $B$ is in 6 ), thus giving $1^{(\mathrm{N}-\mathrm{m})} 3^{\mathrm{m}}$ possibilities, and there are:

for $\mathrm{B}=1$ or 6 we have:

$$
\mathrm{C}_{\mathrm{N}, \mathrm{m}}=\frac{\mathrm{N} !}{\mathrm{m} !(\mathrm{N}-\mathrm{m}) !} \text { ways to choose } \mathrm{m} \text { from } \mathrm{N} \text {, so, }
$$

$$
\mathrm{C}_{\mathrm{N}, \mathrm{m}} \times 3^{\mathrm{m}}
$$

If $\mathrm{B}$ is in 2 or 5 , there are $2^{(\mathrm{N}-\mathrm{m})}$ ways for $(\mathrm{N}-\mathrm{m})$ targets to be detected (by being in 2 or 3 if $\mathrm{B}$ is in 2; or in 4 or 5 if $\mathrm{B}$ is in 5), and $2^{\mathrm{m}}$ ways for them not to be detected (by being in 2 or 3 if $\mathrm{B}$ is in 5 ; or in 4 or 5 if $\mathrm{B}$ is in 2 ), giving for $\mathrm{B}=2$ or 5 :

$$
\mathrm{C}_{\mathrm{N}, \mathrm{m}} \times 2^{(\mathrm{N}-\mathrm{m})} 2^{\mathrm{m}}=\mathrm{C}_{\mathrm{N}, \mathrm{m}} \times 2 \times 2^{\mathrm{N}}
$$

If $\mathrm{B}$ is in 3 or 4 , there are $3^{(\mathrm{N}-\mathrm{m})}$ ways for $(\mathrm{N}-\mathrm{m})$ targets to be detected (by being in 2 , 3, or 4 if $\mathrm{B}$ is in 3 ; or in 3 , 4 , or 5 if $\mathrm{B}$ is in 4 ), and $1^{\mathrm{m}}$ ways for $\mathrm{m}$ targets not to be detected (by being in 5 if $B$ is in 3; or in 3 if $B$ is in 5 ), giving for $B=3$ or 4 :

$$
\mathrm{C}_{\mathrm{N}, \mathrm{m}} \times 2 \times 3^{(\mathrm{N}-\mathrm{m})}
$$

Thus, if B is in any of the 6 possible positions for it ( 1 or 6 or 2 or 5 or 3 or 4 ) we get:

$$
\mathrm{C}_{\mathrm{N}, \mathrm{m}} \times 2 \times\left(3^{\mathrm{m}}+2^{\mathrm{N}}+3^{(\mathrm{N}-\mathrm{m})}\right)
$$

ways for $(\mathrm{N}-\mathrm{m})$ targets to be detected, and $\mathrm{m}$ targets to not be detected.

The total number of possibilities for the game with $\mathrm{N}$ targets are: 6 places for $\mathrm{B}, 4$ places for $\mathrm{A}$, and $\mathrm{N}$ targets, or: $6 \times 4^{\mathrm{N}}$, so the probability distribution over $\mathrm{m}$ is:




As a check on this result, note that $\sum_{\mathrm{m}}{ }^{\mathrm{N}} \mathrm{C}_{\mathrm{n}, \mathrm{m}} 3^{\mathrm{m}}$ (and also for $3^{(\mathrm{N}-\mathrm{m})}$ ) is the binomial expansion of $(1+3)^{\mathrm{m}}=4^{\mathrm{N}}$, and $\sum_{\mathrm{m}}{ }^{\mathrm{N}} \mathrm{C}_{\mathrm{N}, \mathrm{m}}$ is the binomial expansion of $(1+1)^{\mathrm{N}}=2^{\mathrm{N}}$, so:

$$
\left.\sum{ }_{\mathrm{m}}^{\mathrm{N}} \mathrm{C}_{\mathrm{N}, \mathrm{m}}\left(3^{\mathrm{m}}+2^{\mathrm{N}}+3^{(\mathrm{N}-\mathrm{m})}\right)=4^{\mathrm{N}}+2^{\mathrm{N}} 2^{\mathrm{N}}+4^{\mathrm{N}}=3 \times 4^{\mathrm{N}}\right)
$$

As a further check, note that when $\mathrm{N}=2$, we get for the probability that all are detected or none are detected $(\mathrm{m}=0$ or $\mathrm{m}=\mathrm{N})$ :

$$
\left(1+2^{2}+3^{2}\right) / 3 \times 4^{2}=(1+4+9) / 3 \times 16=14 / 48=7 / 24,
$$

as obtained in the previous solution by enumeration and counting of possible cases.

\section{VII: A NOTE ON THE FREE ENCOUNTER GENERAL CASE}

As noted earlier, if we assume, naively, that when there are $\mathrm{N}$ separate targets we can treat the result as though it was the same as one target $\mathrm{N}$ times ( $\mathrm{N}$ free encounters), we obtain for $\mathrm{N}-\mathrm{m}$ detected and $\mathrm{m}$ not detected:

$$
\mathrm{P}_{\mathrm{fe}}(\mathrm{m})=\mathrm{C}_{\mathrm{N}, \mathrm{m}} \times 1 / 2^{(\mathrm{N}-\mathrm{m})} \times 1 / 2^{\mathrm{m}}=\mathrm{C}_{\mathrm{N}, \mathrm{m}} \times 1 / 2^{\mathrm{N}}
$$

This is naïve, and incorrect, because it implicitly assumes, contrary to the rules of the game, that the black ball, B, has its position re-randomized before each new target. This is a case of “doing the wrong problem right”, as opposed to “doing the right problem wrong”.

\section{VIII: THE SHAPE OF $\mathrm{P}_{\mathrm{c}}(\mathrm{m})$}

Figures 2 and 3 are histograms of numerical results for $P_{c}(m), P_{f e}(m)$ with $N=20$. An overlay of these two histograms is shown in Figure 4.

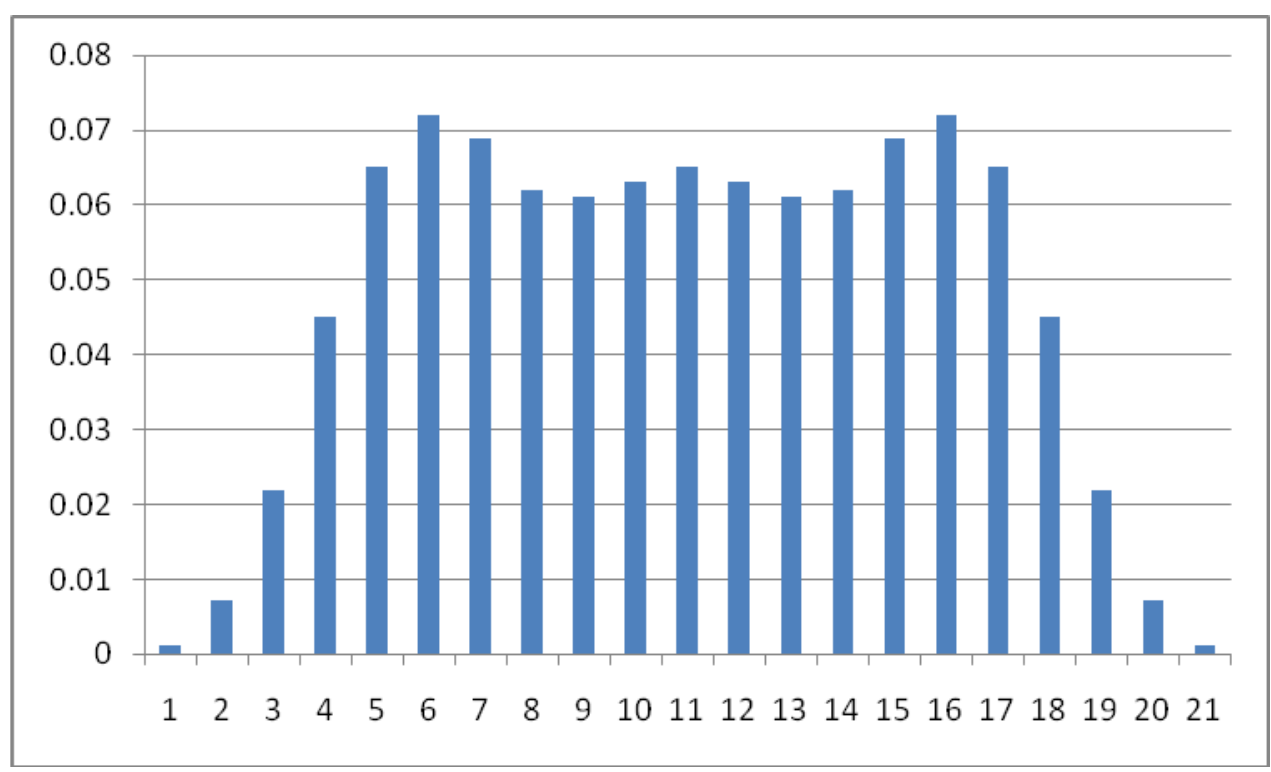

Figure 2: $\mathrm{P}_{\underline{c}} \underline{(20, \mathrm{~m}) \text { vs }(\mathrm{m}+1)}$ 


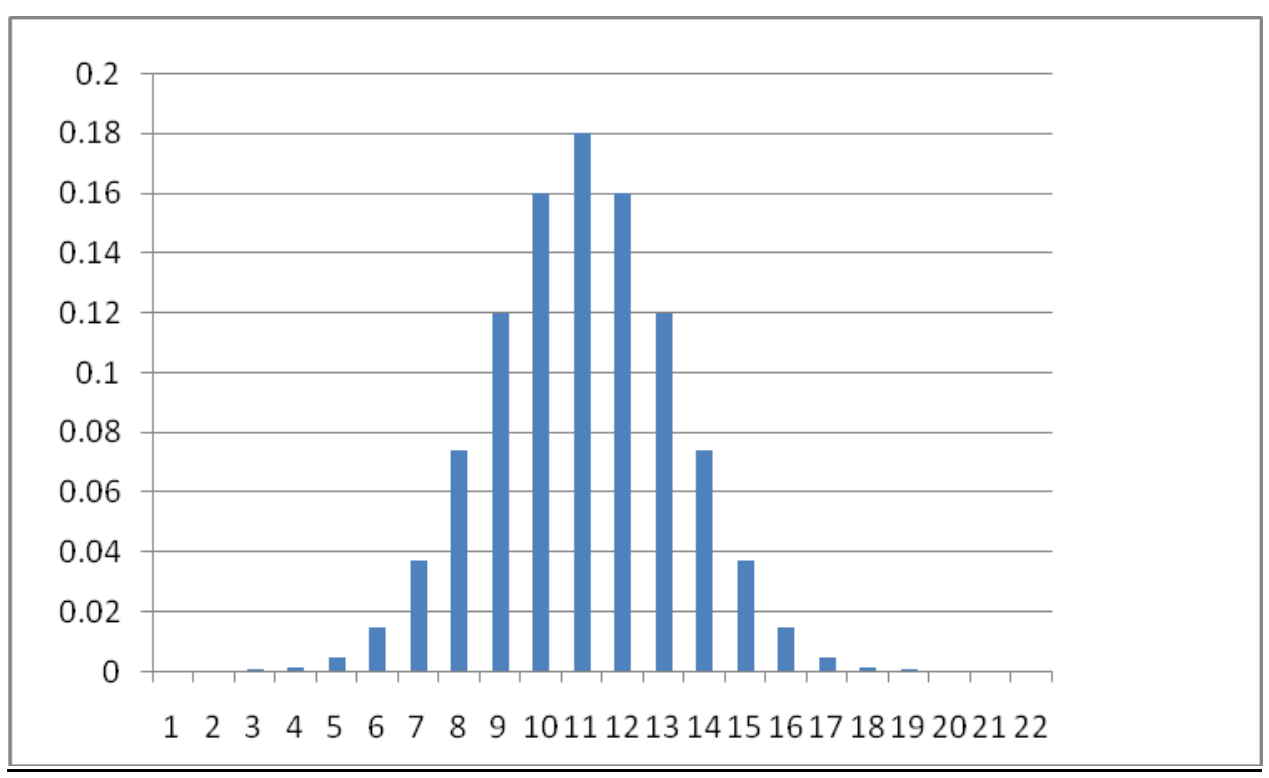

Figure $3 \_: \mathrm{P}_{\mathrm{fe}} \underline{\mathrm{e}}(20, \mathrm{~m})$ vs $(\mathrm{m}+1)$



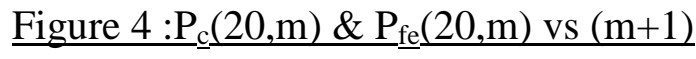


Since $\mathrm{P}_{\mathrm{c}}$ is so flat, and the mean is on a local minimum plateau of the probability distribution, use of the mean value of $\mathrm{P}_{\mathrm{c}}$ to represent the probability distribution would be very misleading.

It is also interesting to examine the ratio:

$$
\mathrm{P}_{\mathrm{c}}(\mathrm{m}) / \mathrm{P}_{\mathrm{fe}}(\mathrm{m})=\frac{3^{\mathrm{m}}+3^{(\mathrm{N}-\mathrm{m})}+2^{\mathrm{N}}}{3 \times 2^{\mathrm{N}}}
$$

A histogram of this ratio is shown in Figure 5.

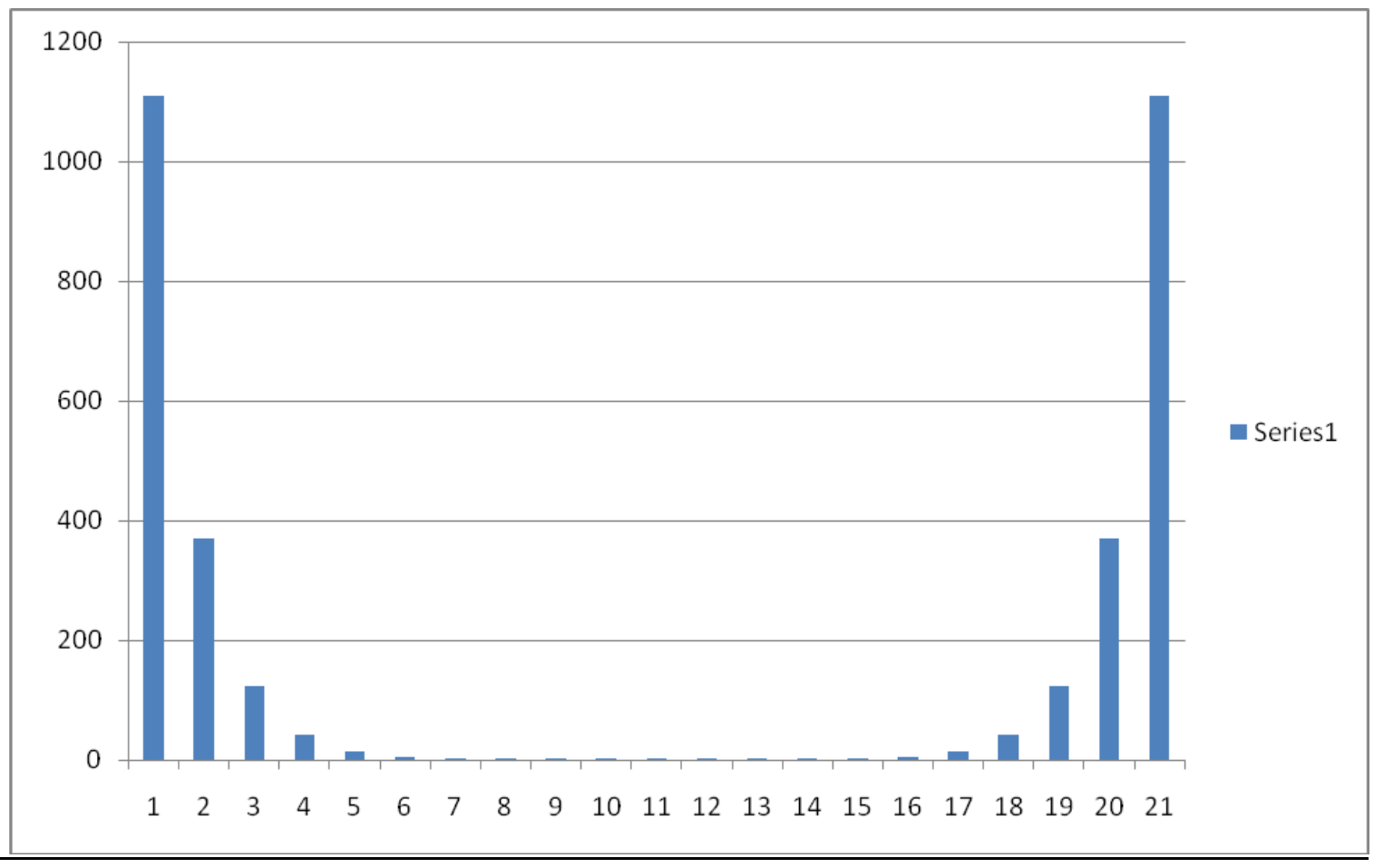

Figure $5: \mathrm{P}_{\underline{c}}(20, m) / \mathrm{P}_{\mathrm{fe}}(20, \mathrm{~m})$ vs $(\mathrm{m}+1)$

The flat center of $\mathrm{P}_{\mathrm{c}}(\mathrm{m})$ is lower than the center of $\mathrm{P}_{\mathrm{fe}}(\mathrm{m})$, the binomial distribution for $\mathrm{p}$ $=1 / 2$, but while the tails of $P_{c}(m)$ at $\mathrm{m}=0$ and $\mathrm{m}-\mathrm{N}$ for $\mathrm{N}=20$ are small, they are 1110 times larger than the tails of the binomial distribution. This means that the probabilities of two interesting extreme cases: all targets are detected, or, no matter how many targets there actually are, none are detected, are three orders of magnitude higher than expected from the (incorrect) free encounter (binomial) distribution. 


\section{IX: SOME INTERESTING VARIANT CASES}

A. Variant 1: $B_{ \pm 5}$

Let us now construct a case in which the range of the detector is increased from $\mathrm{B} \pm 1$ to $\mathrm{B} \pm 5$. The number of possible positions must be increased to maintain the mean probability of detection at $1 / 2$, to maintain comparability with the preceding cases. The truth/event table for $\mathrm{B}_{ \pm 5}$ is shown in Table 4:

$\begin{array}{rrrrrrrrrrrrrrrrrrrrrrr} & 1 & 2 & 3 & 4 & 5 & 6 & 7 & 8 & 9 & 10 & 11 & 12 & 13 & 14 & 15 & 16 & 17 & 18 & 19 & 20 & 21 & 22 \\ 10 & 0 & 0 & 0 & 0 & \mathrm{X} & \mathrm{X} & \mathrm{X} & \mathrm{X} & \mathrm{X} & \mathrm{X} & \mathrm{X} & \mathrm{X} & \mathrm{X} & \mathrm{X} & \mathrm{X} & 0 & 0 & 0 & 0 & 0 & 0 & 0 \\ 11 & 0 & 0 & 0 & 0 & 0 & \mathrm{X} & \mathrm{X} & \mathrm{X} & \mathrm{X} & \mathrm{X} & \mathrm{X} & \mathrm{X} & \mathrm{X} & \mathrm{X} & \mathrm{X} & \mathrm{X} & 0 & 0 & 0 & 0 & 0 & 0 \\ 12 & 0 & 0 & 0 & 0 & 0 & 0 & \mathrm{X} & \mathrm{X} & \mathrm{X} & \mathrm{X} & \mathrm{X} & \mathrm{X} & \mathrm{X} & \mathrm{X} & \mathrm{X} & \mathrm{X} & \mathrm{X} & 0 & 0 & 0 & 0 & 0 \\ 13 & 0 & 0 & 0 & 0 & 0 & 0 & 0 & \mathrm{X} & \mathrm{X} & \mathrm{X} & \mathrm{X} & \mathrm{X} & \mathrm{X} & \mathrm{X} & \mathrm{X} & \mathrm{X} & \mathrm{X} & \mathrm{X} & 0 & 0 & 0 & 0\end{array}$

\section{Table 4: Truth/Event Table of Variant 1 for $\mathrm{B}_{ \pm 5}$}

The black ball may be in any of $1-22$. The white ball may be in any of $10-13$. The mean probability of detection of the white ball $=1 / 2$.

Proceeding as before: if $\mathrm{B}$ is in 1, 2, 3, 4, 19, 20, 21, or 22, the number of possibilities is:

$$
\mathrm{C}_{\mathrm{N}, \mathrm{m}} 0^{(\mathrm{N}-\mathrm{m})} 4^{\mathrm{m}}=\delta_{\mathrm{Nm}} 4^{\mathrm{N}} \text {, }
$$

since $0^{(\mathrm{N}-\mathrm{m})}=0$, unless $\mathrm{m}=\mathrm{N}$, when it $=1$, which we symbolize with the Kronecker $\delta_{\mathrm{Nm}}$.

If $\mathrm{B}$ is in $8,9,10,11,12,13,14$, or 15 the number of possibilities is:

$$
\mathrm{C}_{\mathrm{N}, \mathrm{m}} 0^{\mathrm{m}} 4^{(\mathrm{N}-\mathrm{m})}=\delta_{\mathrm{m} 0} 4^{\mathrm{N}}
$$

For B in 5, or 18 we obtain:

$$
\mathrm{C}_{\mathrm{N}, \mathrm{m}} 1^{(\mathrm{N}-\mathrm{m})} 3^{\mathrm{m}}=\mathrm{C}_{\mathrm{N}, \mathrm{m}} 3^{\mathrm{m}}
$$

For B in 6, or 17 we obtain:

$$
\mathrm{C}_{\mathrm{N}, \mathrm{m}} 2^{(\mathrm{N}-\mathrm{m})} 2^{\mathrm{m}}=\mathrm{C}_{\mathrm{N}, \mathrm{m}} 2^{\mathrm{N}}
$$

For $\mathrm{B}$ in 7 , or 16 we obtain:

$$
\mathrm{C}_{\mathrm{N}, \mathrm{m}} 3^{(\mathrm{N}-\mathrm{m})} 1^{\mathrm{m}}=\mathrm{C}_{\mathrm{N}, \mathrm{m}} 3^{(\mathrm{N}-\mathrm{m})}
$$

There are 22 possible places for $\mathrm{B}, 4$ places for targets, and $\mathrm{N}$ targets, giving $22 \times 4^{\mathrm{N}}$ total possibilities, so, adding all the "or” cases,




Figure 6 shows the shape of this probability function over $\mathrm{m}$ for $\mathrm{N}=20$.

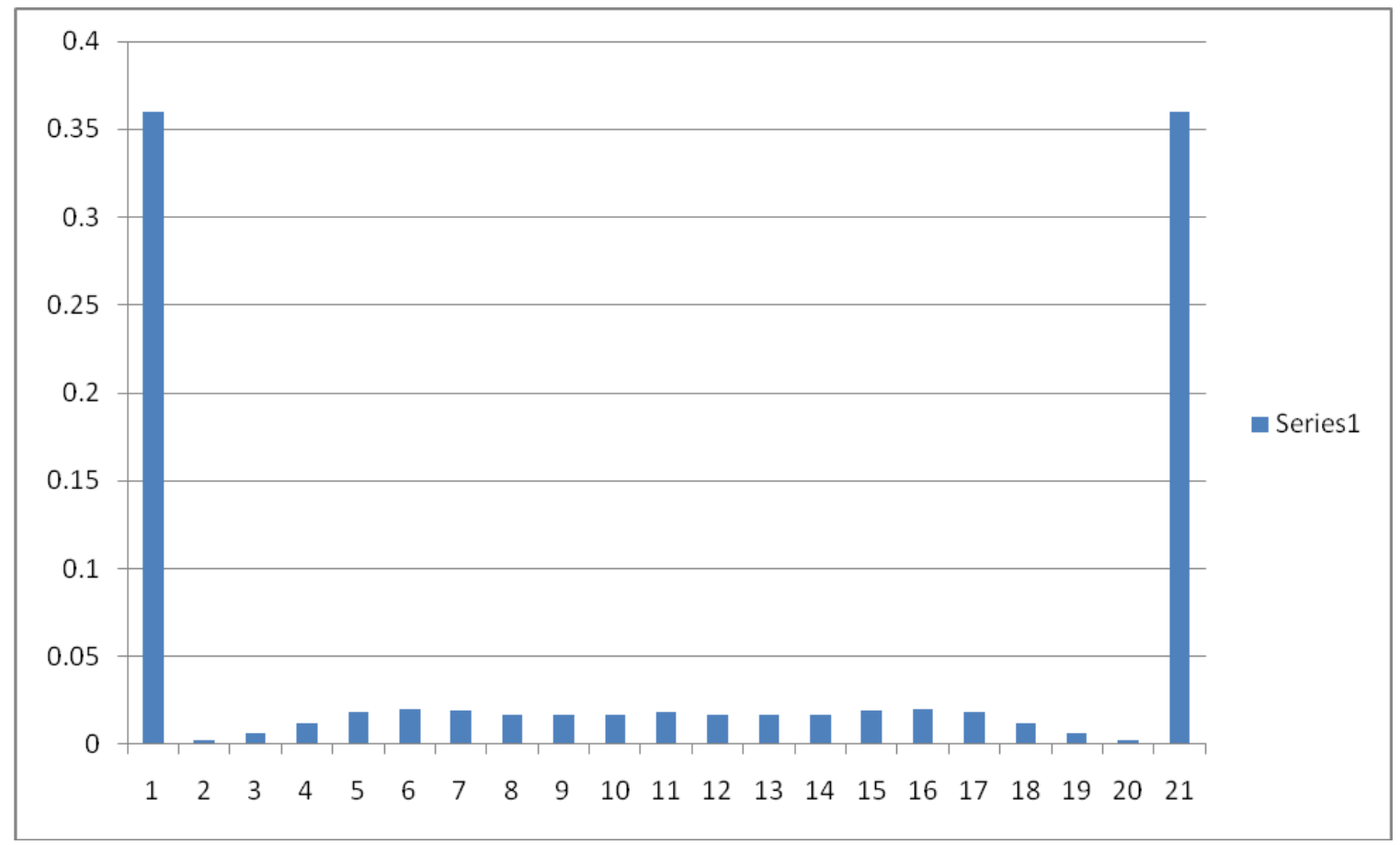

Figure 6 : Histogram for Variant $1, \mathrm{P}_{\mathrm{B} \pm 5}(20, \mathrm{~m})$ vs $(\mathrm{m}+1)$

This result is, again, "not surprising”, since a glance at the truth/event table shows the high likelihood of detecting all or none of the targets. In this case the range of the detector is sufficiently larger than the width of the possible channel for targets that the detector is usually either "out of range", or "in range" of the possible target positions. A free encounter analysis, leading to a binomial distribution (Equation 8, Figure 3), would give a distribution with a central peak and tails on both sides; which is very wrong: it looks somewhat like a distorted inverse of the correct distribution.

\section{B. Variant 2: Inside-out}

It is interesting to construct a variant case (inside-out) in which we interchange the possible places for the black ball and the white ball, while retaining the rule that the black ball, 
once placed by random selection, remains in that place throughout the game. This can be done by allowing the black ball to be only in places 2 through 5, while the white ball can land in any of 1 through 6.

These rules result in Table 5 for Variant 2.

\begin{tabular}{|c|c|c|c|c|c|c|}
\hline & 1 & B2 & B3 & B4 & B5 & 6 \\
\hline W1 & & $X$ & $0 X$ & $0 X$ & $0 X$ & \\
\hline W2 & & $\mathrm{X}$ & $X$ & $0 \mathrm{X}$ & $0 \mathrm{X}$ & \\
\hline W3 & & $X$ & $X$ & $\mathrm{X}$ & $0 \mathrm{X}$ & \\
\hline W4 & & $0 X$ & $X$ & $X$ & $X$ & \\
\hline W5 & & $0 X$ & $0 X$ & $X$ & $X$ & \\
\hline W6 & & $0 X$ & $0 X$ & $0 X$ & $X$ & \\
\hline
\end{tabular}

Table 5: Truth/Event Table for Variant 2

If $\mathrm{B}$ is anywhere from 2 to 5, it is always the case that white balls in three of the possible positions for white (1 through 6 ) are detected, and white balls in three of the possible positions for white (1 through 6 ) are not detected. The general case for $\mathrm{N}$ targets, with $\mathrm{N}$-m detected and $\mathrm{m}$ targets not detected thus gives $3^{(\mathrm{N}-\mathrm{m})}$ detected, and $3^{\mathrm{m}}$ not detected, or $4 \times 3^{(\mathrm{N}-\mathrm{m})} \times 3^{\mathrm{m}}=4 \times 3^{\mathrm{N}}$ possibilities, and thus the probability density over $\mathrm{m}$ is:

$$
\mathrm{P}_{\mathrm{io}}=\mathrm{C}_{\mathrm{N}, \mathrm{m}} \frac{4 \times 3^{\mathrm{N}}}{4 \times 6^{\mathrm{N}}}=\underline{\mathrm{C}}_{\mathrm{N,m}}=\mathrm{P}_{\mathrm{fe}}
$$

This, of course, the same as the result for the naïve free encounter case, the Binomial Distribution for $p=1 / 2$. This result is not surprising if we note that the probability that the black ball is in position $\mathrm{i}$, conditional upon the location of the white ball, is the same for all positions of the white ball: $3 / 12=1 / 4$.

An identical result is obtained for the inside-out case for $\mathrm{B}_{ \pm 5}: \mathrm{P}_{ \pm 5}(\mathrm{~N}, \mathrm{~m})=\mathrm{P}_{\mathrm{fe}}(\mathrm{N}, \mathrm{m})$

\section{Variant 3: A Missing B position}

We return to the $\mathrm{B} \pm 1$ case, but now the black ball may be in 1,2 , 4 , or 5 , but not in 3 , while the white ball may be in 2, 3, or 4 .

The truth/event table for Variant 3 is shown in Table 6, with: $\mathrm{P}_{\mathrm{MB}}(\mathrm{X})=\mathrm{P}_{\mathrm{MB}}(0 \mathrm{X})=1 / 2$.






$$
\text { W4 } 0 \mathrm{X} \quad \text { OX } \quad \mathrm{X} \quad \mathrm{X}
$$

Table 6: Truth/Event table for Variant 3

We proceed as before, obtaining:

$$
\mathrm{P}_{\mathrm{MB}}(\mathrm{N}, \mathrm{m})=\underline{\mathrm{C}}_{\mathrm{N}, \mathrm{m}} \frac{\left(2^{\mathrm{m}}+2^{(\mathrm{N}-\mathrm{m})}\right)}{2 \times 3^{\mathrm{N}}}
$$

Figures 7, 8, and 9 are histograms of $\mathrm{P}_{\mathrm{MB}}(20, \mathrm{~m}), \mathrm{P}_{\mathrm{MB}}(20, \mathrm{~m}) \& \mathrm{P}_{\mathrm{fe}}(20, \mathrm{~m})$ together, and $\mathrm{P}_{\mathrm{MB}}(20, \mathrm{~m}) / \mathrm{P}_{\mathrm{fe}}(20 / \mathrm{m})$ for Variant 3.

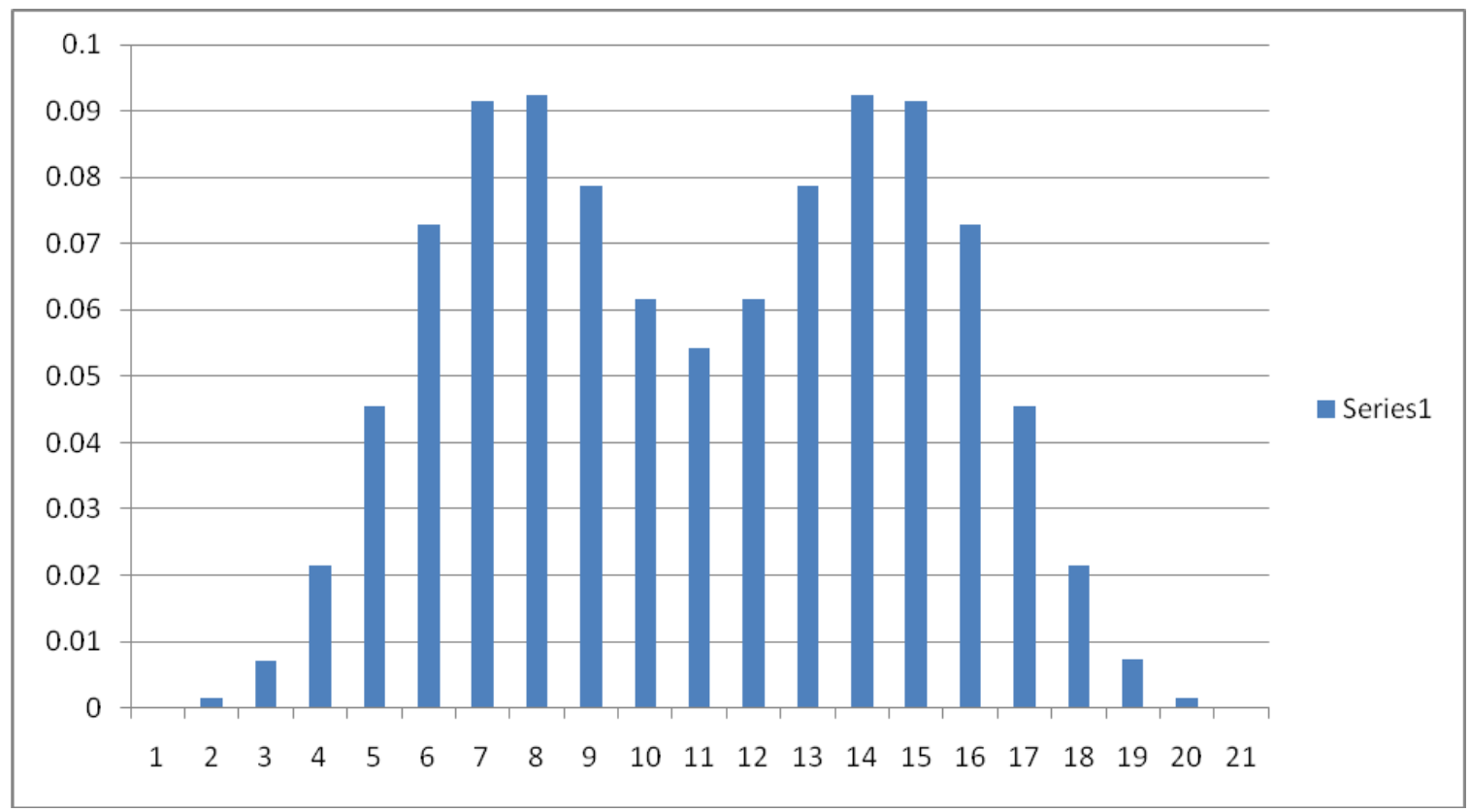

Figure 7: Histogram for Variant $3, \mathrm{P}_{\mathrm{MB}}(20, \mathrm{~m})$ vs $(\mathrm{m}+1)$ 




Figure 8: Histogram for Variant 3, $\mathrm{P}_{\mathrm{MB}}(20, \mathrm{~m}) \& \mathrm{P}_{\mathrm{fe}}(20, \mathrm{~m})$ vs $(\mathrm{m}+1)$

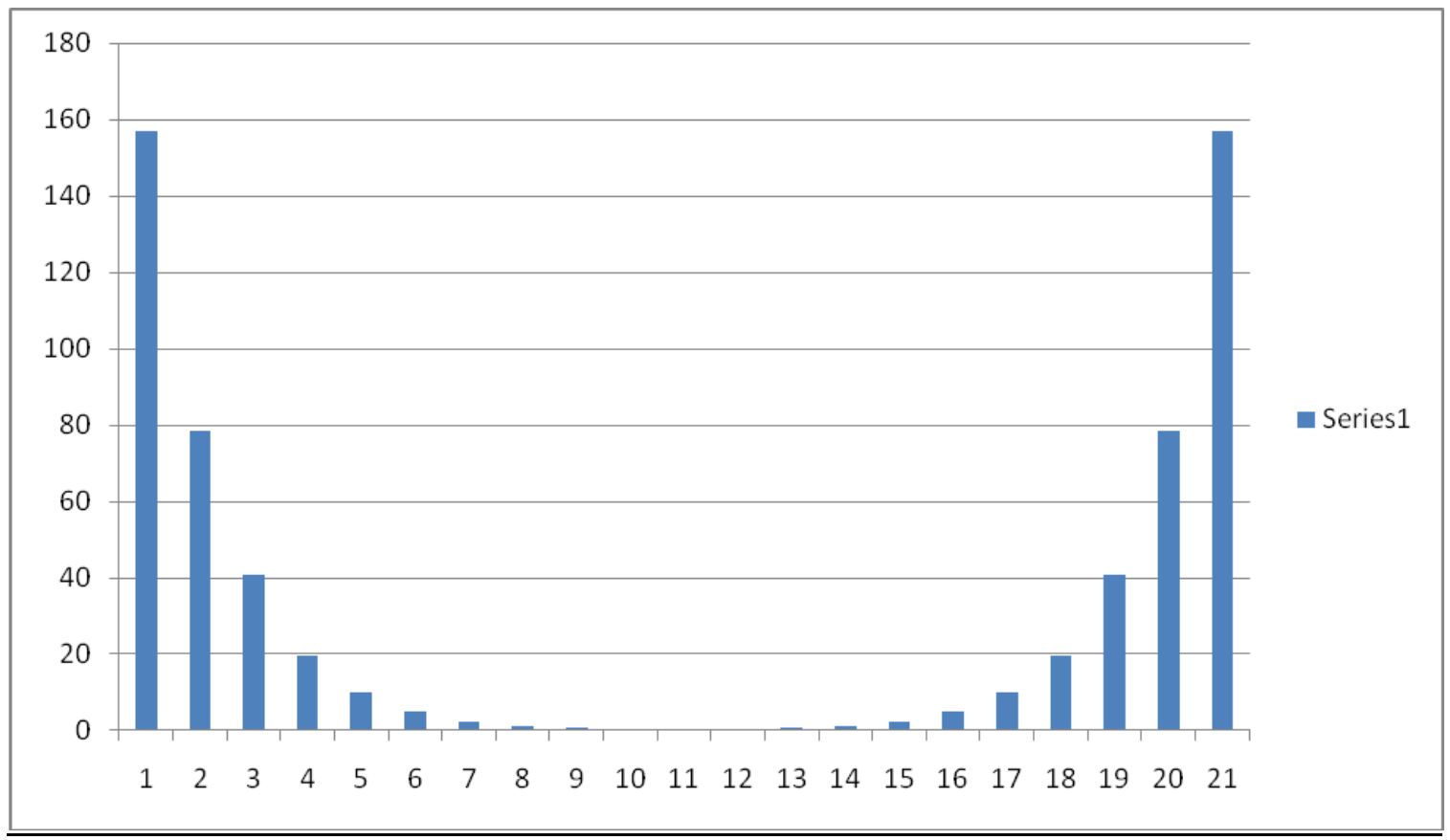

Figure 9: Histogram for Variant 3, $\mathrm{P}_{\mathrm{MB}}(20, \mathrm{~m}) / \mathrm{P}_{\mathrm{fe}}(20, \mathrm{~m})$ vs $(\mathrm{m}+1)$ 


\section{BINOMIAL OR NOT?}

When the possible positions for the target surround (bracket) the possible positions of the detector, we obtain a binomial (free encounter) distribution. When the possible positions of the detector surround (bracket) the possible positions of the target, we obtain a non-binomial, flatter, sometimes double-peaked, distribution.

\section{EXAMPLES OF POSSIBLE REAL SITUATIONS}

There are a number of real situations in which the "anomalous" (non-binomial) distributions will occur, or where it might be advantageous to create a configuration of detectors in which they are likely to occur. These include the following:

1. Any spatial situation in which geography restricts targets to a corridor. For example, harbor entrances, straits, such as Malacca, the entrance to the Tongue of the Ocean in the Bahamas, the approaches to Stellwagen Bank, near Cape Cod, and any channeled situation.

The corridor might be vertical, eg: organisms to be detected might be restricted to a particular depth interval. In this case it would matter whether the detector: 1 . might be above, below, or in the same depth interval as the organisms, or 2. whether it can only be at depths within the depth corridor occupied by the organisms. In case 2. The probability of detection distribution will be binomial, while in case 1 . it will be like $\mathrm{P}_{\mathrm{c}}$, configural.

2. Any situation, such as a search for endangered species (eg blue whales, bluefin tuna) in which it might be advantageous to greatly increase the probability of detecting all, even at the possible price of increasing the probability of detecting none.

3. Alternatively, if a binomial distribution would be advantageous, the detectors can be purposely embedded inside the field of possible target location. Such situations are common, even usual in open ocean detection situations.

4. Many military situations, including naval mine fields blocking waters in which ships are constrained in where they may go (eg harbor or beach approaches), and including many antiair situations (eg in which some military reason constrains the corridors through which attacking or transiting aircraft may fly) exhibit configural effects, and will exhibit non-binomial distributions. 


\section{XII: CONCLUSIONS}

The analysis presented demonstrates that the addition of a configural dimension (here taken to be the places where the black and white balls may be in a space of discrete positions) changes the nature of the probability distributions. Targets that enter separately may not necessarily have fates that are probabilistically independent, and the resulting distributions bear little resemblance to the usually expected binomial distribution.

These effects need to be kept in mind, and taken into account, in designing and analyzing detection experiments and systems.

While the phraseology of this paper was in terms of detection systems, of course the same analysis applies to weapons systems and warfare encounters, in which black and white may represent defenders and targets, as well as in other kinds of two actor encounters.

\section{ACKNOWLEDGEMENTS}

This analysis is a very simple example of a fundamental aspect of configural theory, developed by T. J. Horrigan of Horrigan Analytics [3] originally for the analysis and design of Naval mine warfare systems, encounters, and battles, and later applied to other forms of warfare, including anti-aircraft vs aircraft and missile systems, etc. Configural Theory was endorsed and recommended to the Navy for its use by several National Research Council Reports [4][5], the most recent being [5].

In the game presented above, the four adjacent boxes that may be occupied by a target are the analogue of the Attack Corridor in configural theory. The row of six boxes, one of which is occupied by an intruder, corresponds to the Interaction Corridor. In the configural analysis context, it is a subrow of a generally much longer row of boxes, every seventh one of which contains a black ball emplaced by the defender. (EG: a mine field with evenly spaced mines, or an anti-aircraft setup with evenly spaced anti-aircraft guns or missiles.) The position of the Attack Corridor, which the target must select without knowledge of the locations of the black balls, determines the subrow of six boxes that is the analogue of the Interaction Corridor.

In the analogue, the boxes adjacent to the ends of the Attack Corridor are the Encounter

Zones. The Attack Corridor and its Encounter Zones define the Interaction Corridor. Finally, the 
subrow of three adjacent boxes centered on the box with the black ball and within any of which a white ball is killed is the analogue of the Encounter Region of the defender weapon.

The analysis presented here is based on a 1978 Ball-and-Urn Illustration of an Idealized Configured Encounter devised by Derrill J. Bordelon (then of the US Navy Underwater Systems Center, Newport, RI), as reconstructed by T.J. Horrigan of Horrigan Analytics. The original analysis has been greatly simplified and then extended. That analysis, which used chained probability formulas, was difficult for the non-probabilist to follow, and did not lend itself to extension beyond two targets. John Bailar, Professor Emeritus, University of Chicago, IOM) pointed out that it was straightforward to reach the two target result directly by constructing the truth/event table. That analysis led to the generalization of the results using combinatorial algebra, as presented in this paper.

I have also benefited greatly from discussions with T. J. Horrigan of Horrigan Analytics, who invented configural theory, introduced me configural theory, to the Bordelon problem, and suggested the $\mathrm{B}_{ \pm 5}$ case.

I thank James Lynch of WHOI for many illuminating discussions in the course of this work.

\section{REFERENCES}

[1] See eg: W.F. Feller, An Introduction to Probability Theory and its Applications, Third Edition, 1968, John Wiley \& Sons

[2] Google the “Monty Hall Problem”. The Wikipedia article is very helpful, and lists a number of useful scholarly and popular references. Two useful and interesting references are: S. Selvin, et al, A Problem in Probability, The American Statistician, v. 29, p. 67, Feb, 1975, R.D. Gill, The Three Doors Problem, arXiv:1002.3878v2 [stat.AP] 1 Mar 2010

[3] See eg: T. J. Horrigan, Configuration and the Effectiveness of Air Defense Systems in Simplified, Idealized Combat Situations --- A Preliminary Examination, horrigan analytics, Chicago, IL,1995, Horrigan Analytics Document \# HA 90 - 1. 
[4] Naval Studies Board, National Research Council, Report of the Mine Warfare Study Group Volume II Minefield Theory (U) (Secret), National Academy Press, April 1981;

[5] Naval Studies Board, National Research Council, Technology for the U.S. Navy and Marine Corps, 2000-2035: Becoming a $21^{\text {st }}$-Century force; Vol 7, Undersea Warfare, Pages 78-79, and vol. 9: Modeling and Simulation, Page 9, and Appendix J, Pages 233-238: Probabilistic Dependencies in Combat Models, National Academy Press, 1997 